\title{
The Quality of Public Opinion Poll Coverage during German Federal Election
}

\section{Campaigns}

Abstract

We analyzed the quality of opinion poll coverage during the German Federal Election Campaigns 2005, 2009, 2013 and 2017 with a quantitative content analysis of the German quality newspapers Die Welt, Frankfurter Allgemeine Zeitung, Süddeutsche Zeitung and Frankfurter Rundschau. From the literature, we derived three indicators of high quality poll coverage: 1) Identification the source of the reported poll, 2) inclusion of the most important methodological information of these polls, and 3) correct interpretation of the poll results with regard to the margin of error. In line with previous research, the poll coverage lacked quality according to all three criteria. We conclude with a discussion of some simple remedies to improve the public opinion poll coverage.

Keywords

Quality of poll coverage, content analysis, opinion polls, election campaigns 


\section{The Quality of Public Opinion Poll Coverage during German Federal Election}

\section{Campaigns}

\section{Introduction}

It is hardly possible to image modern election campaign coverage without reports about the most recent public opinion polls (Brettschneider, 2008; Holtz-Bacha, 2012; Lavrkas \& Bauman, 1995; Strömbäck, 2009). Opinion polls are newsworthy because they can help them to gain an overview of the public's evaluation of parties, candidates and issues (Moy \& Rinke, 2012). There is some empirical evidence that poll reporting has the potential to affect voters' attitudes and behavior, for example voting turnout and preferences (Hardmeier, 2008; Moy \& Rinke, 2012). Therefore, it is crucially important that poll results are reported accurately and interpreted correctly in the news. However, the quality of poll reports was often described as lacking (Brettschneider, 2008; Patterson, 2005). The criticism revolved mainly around three main points (Brettschneider, 2008; Donsbach, 2001).

First, journalists often refer to poll results in general without mentioning the specific poll. Expressions like 'polls show' are often used loosely to explain and reinforce journalistic interpretations (Brettschneider, 2008). Studies showed that such unspecific references to polls were highly prevalent in the media coverage of various countries (Andersen, 2000; Brettschneider, 1997, 2003; Frankovic, 1998). A vague presentation of poll results is a defining part of the so-called horse-race election coverage which frames politics as a race between the different parties and candidates using polling data as benchmark (Jamieson, 1992; Patterson, 1993). "Polls fit nicely into this game-centered perspective. They supply the data that enable U.S. reporters to tell their audience who is ahead and who is behind" (Patterson, 2005, p. 718). Several studies established the game-framing of elections with 
opinion polls, especially in the United States, which comes at the expense of political issues (e.g., Larson, 2003; Stovall \& Soloman, 1984; Wheeler, 1990).

Second, journalists tend to omit most of the methodological information about a poll, such as sample size, question wording, or the time of fieldwork. The missing methodological transparency is problematic, because it makes it hard or even impossible to evaluate the poll's quality (Brettschneider, 2008; Welch, 2002). For that reason, professional organizations, such as the American Association for Public Opinion Research (AAPOR), the World Association for Public Opinion Research (WAPOR), and the European Society for Market and Opinion Research (ESOMAR) have published guidelines for the disclosure of methodological information in poll publications. For example, the AAPOR's Code of Ethics states: “Good professional practice imposes the obligation upon all public opinion and survey researchers to disclose sufficient information about how the research was conducted to allow for independent review and verification of research claims" (AAPOR, 2015, p. 7). According to the AAPOR-guideline the following methodological details should be included in poll reports among other things: name of the survey institute and the poll's sponsor, the definition of the survey population, the sample size, the response rate, the time of fieldwork, the question wording, the margin of error, and the mode of data collection (AAPOR, 2015, p. 4-5). The press code of conduct issued by the German Press Council mentions similar points in their recommendations on how to report on survey results (German Press Council, 2015, p. 4). Many scholars agreed that requirements like the AAPOR criteria should also hold for journalistic poll coverage. However, content analyses repeatedly showed that the inclusion of methodological details in poll coverage left much to be desired (in Germany: Brettschneider, 2003, 2008; Holtz-Bacha, 2014; Raupp, 2007; in the U.S.: Welch, 2002; in Canada: Andersen, 2000; Ferguson \& de Clercy, 2005; in Sweden: Strömbäck, 2009). The most frequently reported methodological information was the name of the polling institute, 
followed by the poll's sponsor. But other important methodological aspects, like the interview method, the response rate, the question wording, or the margin of error, were rarely disclosed. The information was therefore often inadequate to enable well founded conclusions about the poll's quality. Using the professional organizations' guidelines as reference, the quality of many articles with public opinion polls could be considered poor.

Third, it is often criticized that journalists misrepresent the empirical evidence from poll results. Larson (2003) examined the interpretation of poll results in US networks evening news during the 2000 presidential election. Slightly more than half of the reports about specific polls included information about the margin of error at all, and nearly half of these results were, in turn, interpreted incorrectly. Bhatti and Pedersen (2016), Pétry and Bastian (2013), and Tryggvason and Strömbäck (2017) calculated the empirical $z$-values of comparisons in the poll coverage in order to gauge the statistical evidence for the journalists' statements. All three studies showed that many comparative statements were not backed by the statistical evidence. The studies analyzed different types of comparisons: Diachronic comparisons refer to comparisons of the same object (party or politicians) over time, i.e., across subsequent polls; Synchronous comparisons refer to comparisons between two objects at the same time, i.e., within one poll. Pétry and Bastien (2013) reported that only $11,7 \%$ of the synchronous comparisons, but $44,5 \%$ of the diachronic comparisons were interpreted inaccurately in four television evening news and four newspapers during the 2008 Canadian federal election campaign. Tryggvason and Strömbäck (2017) analyzed diachronic comparisons and comparisons with the electoral threshold in three Swedish newspapers in two election years and in two non-election years. Bhatti and Pedersen (2016) included diachronic and synchronous comparisons and comparisons with the electoral threshold and previous election results in seven newspapers during the 2011 Danish parliamentary election campaign. Both studies did not differentiate their results by type of comparison, but found 
that about two thirds of the comparisons, which were interpreted as a difference by the journalists, lay within the margin of error.

Overall, we conclude from the literature that journalists should meet the three requirements in order to provide high quality poll coverage. They should 1) identify the specific poll which is the source for the reported results, 2) include the most important methodological information of these polls, and 3) correctly interpret the poll results bearing in mind the margin of error. Most empirical evaluations gave a rather negative verdict on the quality of the poll coverage against this standard. We contribute to this research with an evaluation of the poll coverage prior to the four most recent German federal elections.

\section{Methods $^{1}$}

Sample. We conducted a quantitative content analysis to assess the quality of poll reports in the German newspaper coverage. We selected Die Welt, Frankfurter Allgemeine Zeitung, Süddeutsche Zeitung and Frankfurter Rundschau, because the national quality newspapers in particular can be expected to meet the quality standards of poll coverage. All articles in the 12 weeks prior to the German federal elections 2005, 2009, 2013 and 2017, which reported on current survey results concerning the federal election or on public opinion research in general, were included in the sample. ${ }^{2}$

Coding units and measures. We used two coding units, articles $(n=1,409)$ and comparisons $(n=1,616)$. For all articles, which did report recent poll results $(n=1,231)$, it was recorded whether the specific poll was identified (e.g., "the recent poll by Infratest showed...") and how important the poll results were within the article. For all articles, in which the poll results were the dominant topic $(n=220)$, it was coded whether the following seven methodological details, which are part of the AAPOR guideline (AAPOR, 2015), were reported: name of survey institute, definition of survey population, sample size, time of 
fieldwork, question wording, margin of error, and mode of data collection. The main data collection was conducted by three coders. An intercoder reliability test with 36 articles showed satisfying chance-corrected agreement at the article level. ${ }^{3}$ In addition, we recorded information about three types of comparisons: 1) synchronous comparisons between two objects (i.e., parties or politicians) in the same poll (e.g., "The Social Democrats trailed the Conservatives by 5 percentage points"); 2) diachronic comparisons of the same object between two polls (e.g., "The Social Democrats lost 2 percentage points compared to last month's poll"); 3) combined synchronous and diachronic comparisons of the differences between two objects in two polls (hereafter: combined comparisons; e.g., "The lead of the Conservatives on the Social Democrats has increased by 1 percentage point"). $89 \%$ of the comparisons in the 36 test articles were identified unanimously by all three coders, which can be considered sufficiently reliable. Overall, 289 synchronous, 1,250 diachronic, and 77 combined comparisons were found. An additional coder collected the statistical information, which is necessary to quantify the empirical evidence for a comparison (proportions and sample sizes, see subsequent paragraph for details), from the articles. The proportions were available for 116 synchronous, 726 diachronic, and 35 combined comparisons. The sample sizes were missing for a small number of these comparisons (24 synchronous, 74 diachronic, and 3 combined comparisons). We replaced the missing sample sizes by the median sample size of the respective comparison type to be able to include the cases in the analysis. ${ }^{4}$

Quantification of the empirical evidence. The statistical evidence for the comparisons was quantified by the $z$ score, that is, by dividing the estimated difference of interest by its standard error. Higher $z$ scores indicate stronger evidence for the difference being different from zero. A $z$ score of 1.96 indicates the confidence level of $95 \%$, which is the most common critical value in the social sciences to conclude that the difference is non-zero. ${ }^{5}$ The 
standard error of the difference between two proportions from the same survey (synchronous comparison) is

$$
\sqrt{\frac{p_{1}+p_{2}-\left(p_{1}-p_{2}\right)^{2}}{n}}
$$

where $p_{1}$ and $p_{2}$ are the proportions in the comparison and $n$ is the sample size of the survey (Scott \& Seber, 1983). The standard error of the difference between two proportions from two independent surveys is

$$
\sqrt{\frac{p_{1} *\left(1-p_{1}\right)}{n_{1}}+\frac{p_{2} *\left(1-p_{2}\right)}{n_{2}}}
$$

where $p_{1}$ and $p_{2}$ are the proportions in surveys 1 and 2 and $n_{1}$ and $n_{2}$ are the respective sample sizes. The combined comparison asks whether a difference between two proportions from one survey differs from the difference between two proportions from another survey. Consequently, the standard error of the combined difference is

$$
\sqrt{\frac{p_{1,1}+p_{2,1}-\left(p_{1,1}-p_{2,1}\right)^{2}}{n_{1}}+\frac{p_{1,2}+p_{2,2}-\left(p_{1,2}-p_{2,2}\right)^{2}}{n_{2}}}
$$

where the first subscript of $p_{i, j}$ denotes the object of comparison and the second subscript denotes the survey. $n_{1}$ and $n_{2}$ are the sample sizes of the respective surveys. Our analysis dropped the sign of the difference and its $z$ score and distinguished only whether a comparison was interpreted as a difference, i.e., whether the difference between the two proportions was interpreted as different from zero.

\section{Results}

First, we checked whether the journalists reported the source of the poll results to which they referred. Only $32 \%$ of all articles, which discussed poll results, identified the specific poll. The disclosure of the relevant poll was obviously related to the importance of the poll results within the article. $85 \%$ of the articles, which were predominantly about the poll results $(n=$ 
$220)$ and $56 \%$ of the articles, in which the poll results were important $(n=121)$, provided this information. In contrast, a mere $15 \%$ of the articles, which mentioned poll results only in passing $(n=890)$, did so.

Second, we evaluated the methodological transparency in articles, which were predominantly about poll results $(n=220)$, against the standards recommended by the professional associations for public opinion research. The most frequently mentioned detail was the name of the survey institute ( $84 \%) .55 \%$ of the articles reported the question wording, $42 \%$ the population, and $31 \%$ the field time. A quarter of the articles $(26 \%)$ included information about the sample size. The mode of data collection (6\%) and the margin of error (4\%) were mentioned hardly ever. $10 \%$ of the articles did not fulfill a single requirement, whereas $14 \%$ provided information about at least five of the seven criteria.

Third, we checked whether the journalistic interpretations of comparisons were supported by the empirical evidence. Figure 1 shows the distribution of the absolute $z$ values by type of comparison and journalistic interpretation. Across all three types, journalistic interpretations of comparisons as a difference (right column of Figure 1) were by far more frequent than statements of (approximate) equality (left column of Figure 1). It hardly ever occurred that the results for two parties or politicians were described as about equal in a poll (synchronous comparisons) or that the difference between two parties or politicians was considered stable (combined comparisons). In contrast, interpretations of stability made up a substantial share (28\%) of all diachronic comparisons. Almost all (95\%) interpretations of diachronic stability were cases with identical reported point estimates in both surveys. 
The accuracy of interpretations of differences or changes varied substantially by type of comparison. $78 \%$ of the synchronous comparisons were in line with the conventional interpretation of the statistical evidence, i.e. the absolute $z$ value was greater than 1.96. In contrast, only $14 \%$ of the diachronic comparisons, in which the journalist described a party's or a politician's results as having changed over time, were supported by the statistical evidence. The clear majority of so-called changes were within the sampling error of the difference of the two proportions. Similarly, almost all (90\%) interpretations of change in combined comparisons were unsupported by statistical evidence. The statistical evidence frequently did not even come close to support a change over time: $57 \%$ of the diachronic comparisons and $45 \%$ of the combined comparisons, which were described as changes, had absolute $z$ values below 1; that is, the differences were smaller than their standard errors.

\section{Discussion}

In summary, the coverage of public opinion polls before the 2005, 2009, 2013, and 2017 German federal elections in four national quality newspapers lacked quality according to all three criteria, which were evaluated herein. Just about a third of all articles, which mentioned survey results, identified the source of their claims. This finding was mainly driven by the large number of articles which mentioned poll results only in passing and which rarely revealed the specific poll. Such articles can be seen as a symptom of the prevailing horse-race coverage, in which poll results are mainly stylistic devices and not informational content (Larson, 2003). Articles, which focused on the presentation of poll results, were at least far more likely to identify the specific survey. However, further methodological information, which is deemed necessary by professional organizations of survey researchers for an adequate contextualization of a poll, was frequently not given. This finding is in line with previous studies (Andersen, 2000; Brettschneider, 2008; Ferguson \& de Clercy, 2005; Holtz- 
Bacha, 2014; Raupp, 2007; Strömbäck, 2009; Welch, 2002), which also revealed a deficit concerning the disclosure of methodological details in poll reports. Our findings on the empirical evidence for journalistic comparisons suggested that journalists not only omitted methodological details from their articles, but also tended to ignore them when interpreting the poll results. This was especially prevalent in statements of alleged changes over time (diachronic and combined comparisons), which were rarely supported by the data. Only comparisons within the same poll (synchronous comparisons) were usually interpreted correctly. One plausible reason for this contrast could be that the difference between the compared parties or candidates within one poll was usually quite large in our sample. Our results were again in line with previous research (Bhatti \& Pedersen, 2016; Larson, 2003; Pétry \& Bastian, 2013; Tryggvason \& Strömbäck, 2017), indicating that the prevalence of problematic interpretations in the poll coverage in German quality newspapers is no exception, but rather common from a comparative perspective.

Our results have to be considered in the light of some limitations. We discuss three of them, which are, in turn, good starting points for further research, in the following. First, the four newspapers in the sample are certainly not representative for the larger population of poll coverage in Germany. Notably, they are regarded as elite sources which traditionally maintain high journalistic standards. Additional studies of the opinion poll coverage in less well-reputed, but more popular outlets, such as television or Internet news and yellow press or local media outlets, are of course necessary to generalize the results. If the quality of the poll coverage in the quality press showed such deficits, the outlook for mass market media outlets seems gloomy. Second, the approximation of the empirical evidence was rather optimistic, because the simple standard errors only account for the uncertainty due to random sampling error. The total survey error, which includes variation due to measurement error and statistical adjustments, amongst others (Smith, 2011), was found to be up to twice the 
size of the commonly reported margin of error in a recent evaluation of polls in the U.S. (Shirani-Mehr, Rothschild, Goel \& Gelman, 2018). A more advanced study might combine the evaluation of the poll coverage with a detailed analysis of the quality of the polls themselves. Third, we solely focused on the journalistic coverage and thereby ignored the role of the survey institutes. Sumner and colleagues (2014) showed that news articles about medical studies were more likely to exaggerate the results if the university's press release already did so. A similar extension of our study design, which includes interpretations directly issued by the survey institutes, would be worthwhile to distinguish the contributions of their PR offices and of the journalists to unjustified interpretations of polling results.

Our results have implications for the public opinion institutes and their professional organizations, recipients of the poll coverage, and, most importantly, journalists who report on public opinion polls. The providers of public opinion polls could increase their efforts to educate journalists about the importance of methodological details and about the uncertainty in their results. Recipients of the poll coverage must be aware that the poll coverage does often not present all information, which is necessary to evaluate the claims, and that journalistic interpretations, especially of temporal dynamics in the public opinion, are often not supported by empirical evidence. Finally, journalists should pay more attention to a conscious and critical use of poll results in their coverage. Otherwise they provide the public with incomplete poll information and inaccurate interpretations of poll results - with potential impact on voters' attitudes and, possibly, their voting behavior (Hardmeier, 2008; Moy \& Rinke, 2012). Three easy changes can greatly improve the quality of the poll coverage. 1) Journalists should reveal the specific source of every poll result they refer to, even when they mention this result only in passing. Speaking about poll results in general without specifying the survey should be avoided. 2) Journalists should add more information about the method of the reported survey in their reports, for example by adding a technical 
appendix to the article (Brettschneider, 2008). 3) One simple remedy against the large proportion of incorrectly announced changes in public opinion is to ignore changes of 1 percentage point from one survey to another. Such small differences are almost never statistically meaningful given the common sample sizes in public opinion research. Employing this simple rule for our sample would already reduce the unfounded interpretations of so-called changes by over two thirds. The attractiveness of survey results for journalists and the public is unlikely to decrease in the future. It is thus of great importance to regularly check and improve the quality of poll coverage. 


\section{References}

AAPOR (Ed.) (2015). The code of professional ethics and practices (revised 11/30/2015).

Retrieved from: https://www.aapor.org/Standards-Ethics/AAPOR-Code-ofEthics/AAPOR_Code_Accepted_Version_11302015.aspx.

Andersen, R. (2000). Reporting public opinion polls: The media and the 1997 Canadian election. International Journal of Public Opinion Research, 12(3), 285-298. doi:10.1093/ijpor/12.3.000285.

Bhatti, Y., \& Pedersen, R. T. (2016). News reporting of opinion polls: Journalism and statistical noise. International Journal of Public Opinion Research, 28(1), 129-141. doi:10.1093/ijpor/edv008.

Brettschneider, F. (1997). The press and the polls in Germany, 1980-1994. Poll coverage as an essential part of election campaign reporting. International Journal of Public Opinion Research, 9(3), 248-265. doi.org/10.1093/ijpor/9.3.248

Brettschneider, F. (2003). Wahlumfragen: Medienberichterstattung und Wirkungen [Election polls: Media coverage and effects]. In A. M. Wüst (Ed.), Politbarometer. Festschrift für Dieter Roth [Politbarometer. Festschrift for Dieter Roth] (pp. 257-282). Opladen: Leske + Budrich .

Brettschneider, F. (2008). The news media's use of opinion polls. In W. Donsbach \& M. W. Traugott (Eds.), The SAGE Handbook of Public Opinion Research (pp. 479-486). London: Sage.

Donsbach, W. (2001). Who's afraid of election polls? Normative and empirical arguments for the freedom of pre-election surveys. Retrieved from: https://wapor.org/wpcontent/uploads/who-is-afraid-of-opinion-polls.pdf. 
Ferguson, P. A., \& De Clercy, C. (2005). Regulatory compliance in opinion poll reporting during the 2004 Canadian election. Canadian Public Policy/Analyse de Politiques, 31(3), 243-257. doi:10.2307/3552440.

Frankovic, K. (1998). How polling becomes news: Communicating the counting of public opinion. Political Communication, 15(sup1), 1-17. doi:10.1080/10584609.1998.11672656

German Press Council (Ed.) (2015). Publizistische Grundsätze (Pressekodex). Richtlinien für die publizistische Arbeit nach den Empfehlungen des Deutschen Presserats. Beschwerdeordnung. [Publishing principles (press code of conduct). Guidelines and recommendations of the German Press Council. Complaint rules]. Retrieved from: http://www.presserat.de/fileadmin/user_upload/Downloads_Dateien/Pressekodex_B O_2016_web.pdf.

Hardmeier, S. (2008). The effects of published polls on citizens. In W. Donsbach \& M. W. Traugott (Eds.), The SAGE handbook of public opinion research (pp. 504-513). London: Sage.

Hayes, A. F., \& Krippendorff, K. (2007). Answering the call for a standard reliability measure for coding data. Communication Methods \& Measures, 1(1), 77-89. doi: $10.1080 / 19312450709336664$

Holtz-Bacha, C. (2012). Polls, media and the political system. In C. Holtz-Bacha \& J. Strömbäck (Eds.), Opinion polls and the media. Reflecting and shaping public opinion (pp. 267-280). Houndmills: Palgrave Macmillan.

Holtz-Bacha, C. (2014). Politik und Wählerschaft unter Beobachtung: Die Rolle von Umfragen im Wahlkampf [Politics and the electorate under observation. The role of polls during election campaigns]. In C. Holtz-Bacha (Ed.), Die Massenmedien im 
Wahlkampf. Die Bundestagswahl 2013 [Mass media during election campaigns. The German federal election 2013] (pp. 189-215). Wiesbaden: Springer VS.

Jamieson, K. H. (1992). Dirty politics: Deception, distraction and democracy. New York: Oxford University Press.

Larson, S. G. (2003). Misunderstanding margin of error: Network news coverage of polls during the 2000 general election. The International Journal of Press/Politics, 8(1), 66-80. doi: 10.1177/1081180X02238785

Lavrakas, P. J., \& Bauman, S. L. (1995). Page one use of presidential pre-election polls: 1980-1992. In P. J. Lavrakas, M. W. Traugott, \& P. V. Miller (Eds.), Presidential polls and the news media (pp. 35-49). Boulder, San Francisco, Oxford: Westview Press.

Moy, P., \& Rinke, E. M. (2012). Attitudinal and behavioral consequences of published opinion polls. In C. Holtz-Bacha, \& J. Strömbäck (Eds.), Opinion polls and the media: Reflecting and shaping public opinion (pp. 225-245). Houndmills: Palgrave Macmillan.

Patterson, T. E. (1993). Out of order. New York: Alfred A. Knopf.

Patterson, T. E. (2005). Of polls, mountains: U.S. journalists and their use of election surveys. Public Opinion Quarterly, 69(5), 716-724. doi:10.1093/poq/nfi065

Pétry, F., \& Bastien, F. (2013). Follow the pollsters: Inaccuracies in media coverage of the horse-race during the 2008 Canadian election. Canadian Journal of political science, 46(1), 1-26. doi:10.10170S0008423913000188

Raupp, J. (2007). Politische Meinungsforschung: Die Verwendung von Umfragen in der politischen Kommunikation [Political opinion research. The use of polls in political communication]. Konstanz: UVK. 
Scott, A. J., \& Seber, G. A. F. (1983). Difference of proportions from the same survey. The American Statistician, 37(4), 319-320. doi:10.2307/2682774

Shirani-Mehr, H., Rothschild, D., Goel, S., \& Gelman, A. (2018). Disentangling bias and variance in election polls. Journal of the American Statistical Association, 113(522), 607-614. doi:10.1080/01621459.2018.1448823

Smith, T. W. (2011). Refining the total survey error perspective. International Journal of Public Opinion Research, 23(4), 464-484. doi:10.1093/ijpor/edq052

Stovall, J. G., \& Solomon, J. H. (1984). The poll as news event in the 1980 Presidential campaign. Public Opinion Quarterly, 48(3), 615-623. doi:10.1086/268862

Strömbäck, J. (2009). Vox populi or vox media? Opinion polls and the Swedish media, 1998-2006. Javnost - The Public 16(3), 55-70. doi:10.1080/13183222.2009.11009009.

Sumner, P., Vivian-Griffiths, S., Boivin, J., Williams, A., Venetis, C. A., Davies, A., . . Chambers, C. D. (2014). The association between exaggeration in health related science news and academic press releases: Retrospective observational study. $B M J$ : British Medical Journal, 349. doi:10.1136/bmj.g7015

Tryggvason, P. O., \& Strömbäck, J. (2017). Fact or Fiction? Investigating the quality of opinion poll coverage and its antecedents. Journalism Studies, 19(14), 1-20. doi:10.1080/1461670X.2017.1330665

Welch, R. L. (2002). Polls, polls, and more polls: An evaluation of how public opinion polls are reported in newspapers. The International Journal of Press/Politics 7(1), 102114. doi: $10.1177 / 1081180 X 0200700107$

Wheeler, M. (1990). Reining in horserace journalism. In M. Young (Ed.), The Classics of Polling (p. 446-456). London: Scarecrow Press. 


\section{Notes}

${ }^{1}$ The data set and a script to reproduce the results are available at the Open Science Framework: https://osf.io/3urjt/?view_only=5a7bec0c90eb4aeb90d7d20045fefc2a

${ }^{2}$ We used the following databases to retrieve the articles: Frankfurter Rundschau (http://www.nexis.com/), Die Welt (https://www.wiso-net.de), Frankfurter Allgemeine Zeitung (https://www.faz-biblionet.de) und Süddeutsche Zeitung (https://archiv.szarchiv.de). The search term was "Umfrage* OR demoskop* OR Wahlforsch*".

${ }^{3}$ Krippendorff's $\alpha$ : identification of specific poll $=1.0$; importance of poll results within article $=.83$; name of survey institute $=.92$; definition of survey population $=.73$; sample size $=1.0 ;$ time of fieldwork $=.93 ;$ question wording $=.8 ;$ margin of error $=1.0 ;$ mode of data collection $=.84$ (computed with Hayes \& Krippendorff, 2007).

${ }^{4}$ The exact sample size does not matter so much for the standard error calculations (see the formulas in the subsequent paragraph) and the typical sample sizes did not vary much between polls. An analysis without these cases yielded the same substantial results (see replication code).

${ }^{5}$ This assumes two-sided tests. We assumed that journalists usually do not test a one-sided hypothesis, but want to know whether, for example, a party has gained or lost approval compared to the previous poll. 

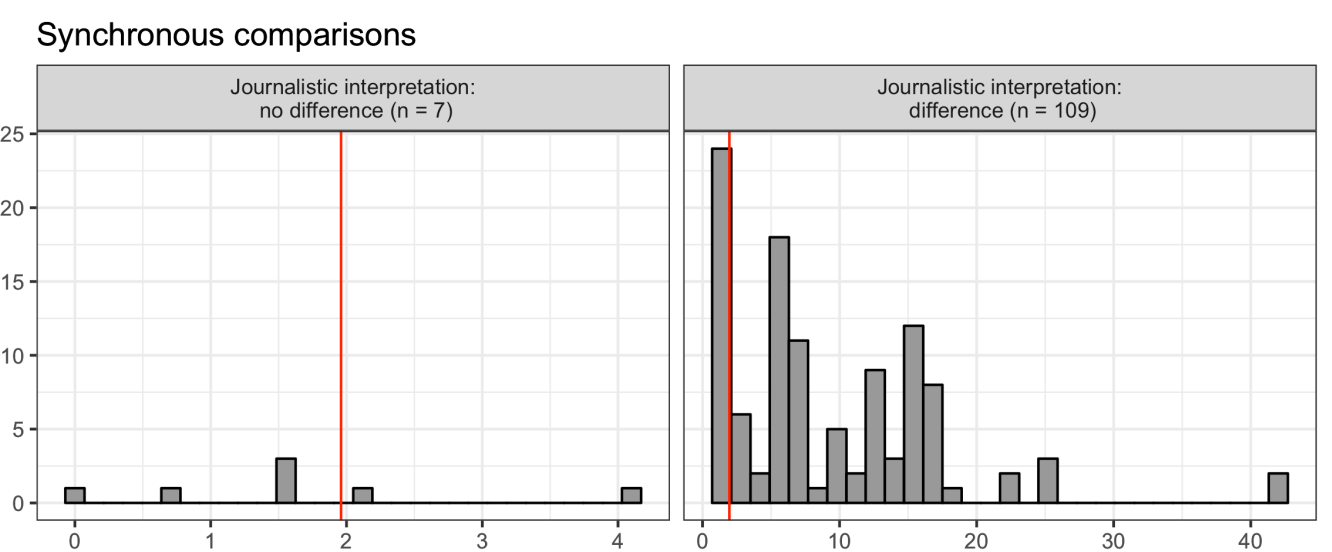

Diachronous comparisons
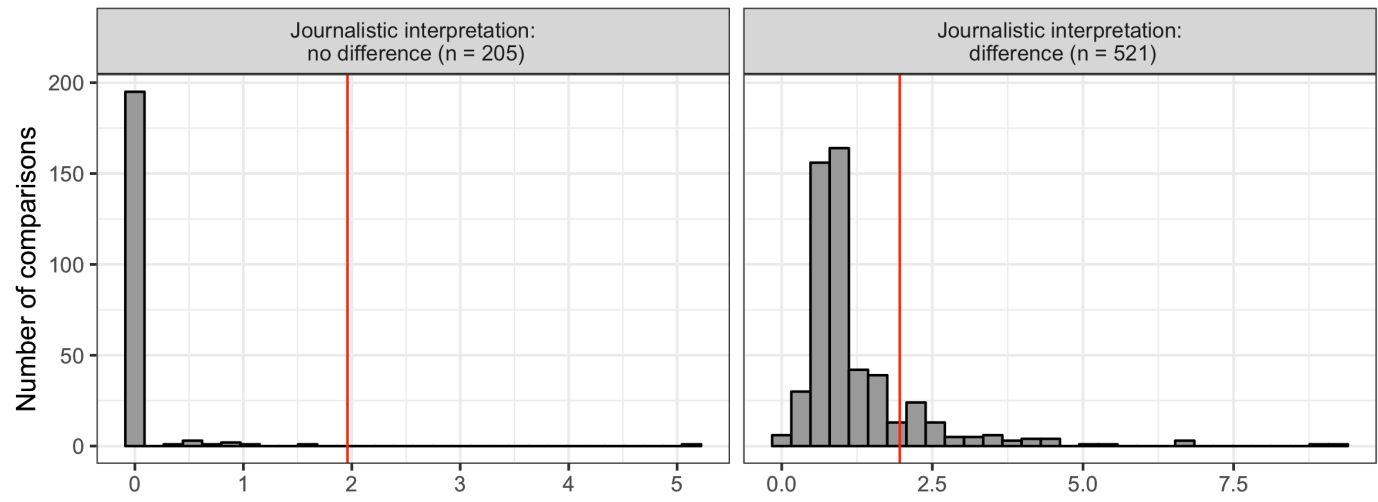

Combined comparisons

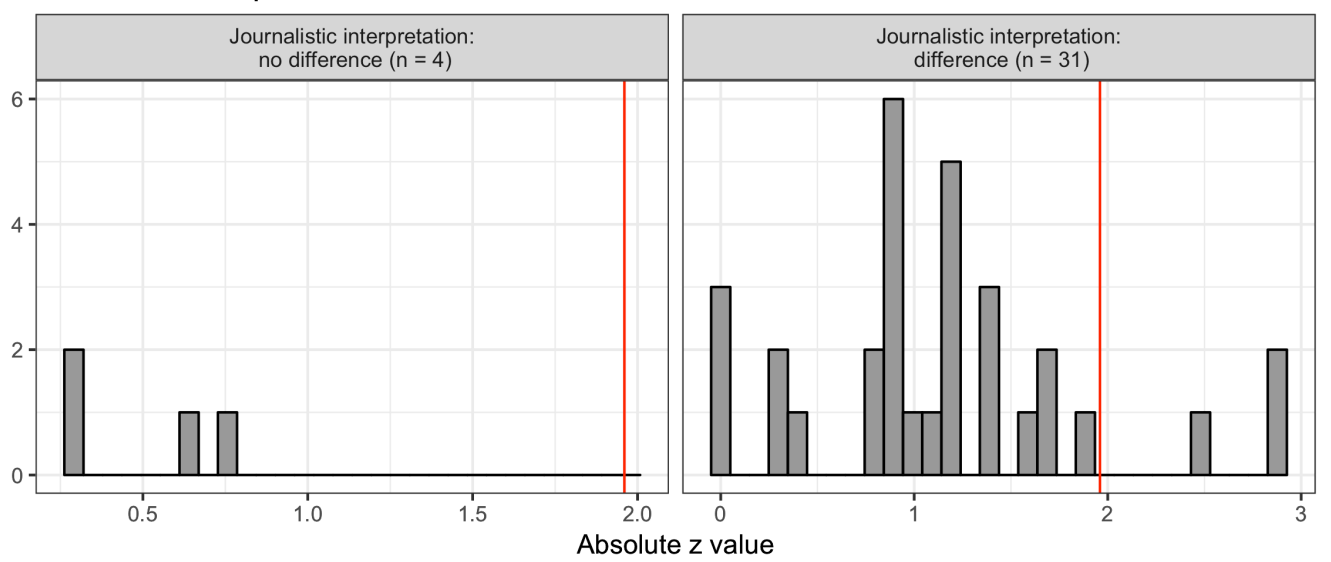

Notes. The figure shows histograms of the distributions of the absolute $z$ values by type of comparisons in the rows and the journalistic interpretation in the columns. Note the different scaling of the $\mathrm{x}$ and $\mathrm{y}$ axes. The $\mathrm{x}$ axis shows the absolute $z$ value of the comparison, with the common $95 \%$ confidence level highlighted by the red lines at $z=1.96$. The y axis shows frequency counts.

Figure 1: Distribution of absolute $z$ values for the three different types of comparison 